\title{
Papers
}

\section{Is there a familial link between Down's syndrome and neural tube defects? Population and familial survey}

Márcia R Amorim, Eduardo E Castilla, Iêda M Orioli

\begin{abstract}
Objective To verify whether Down's syndrome and neural tube defects arise more often in the same family than expected by chance.

Design Population and familial survey.

Setting Network of maternity hospitals in the Latin American collaborative study of congenital malformations (ECLAMC) in Argentina, Bolivia, Brazil, Chile, Colombia, Ecuador, Paraguay, Peru, Uruguay, and Venezuela between 1982 and 2000.

Probands 2421 cases of neural tube defects, 952 of

hydrocephalus, and 3095 of Down's syndrome registered from a total of 1583838 live births and stillbirths.

Main outcome measures Observed number of cases of Down's syndrome among siblings of probands with a neural tube defect or hydrocephalus and number expected on the basis of maternal age; observed number of cases of neural tube defects or hydrocephalus among siblings of probands with Down's syndrome and number expected according to the prevalence in the same population.

Results Five cases of Down's syndrome occurred among 5404 pregnancies previous to a case of neural tube defect or hydrocephalus, compared with 5.13 expected after adjustment by maternal age. Twelve cases of neural tube defect or hydrocephalus occurred among 8066 pregnancies previous to a case of Down's syndrome, compared with 17.18 expected on the basis of the birth prevalence for neural tube defects plus hydrocephalus in the same population.

Conclusion No association occurred between families at risk of neural tube defects and those at risk of Down's syndrome.
\end{abstract}

\section{Introduction}

An association between abnormal intake or metabolism of folate and neural tube defects has been proved. ${ }^{1-3}$ At the molecular level, the $677 \mathrm{C} \rightarrow \mathrm{T}$ (alanine to valine) polymorphism in the gene encoding the folate metabolising enzyme methylenetetrahydrofolate reductase constitutes a genetic risk for neural tube defects in some parts of the world but not in others. ${ }^{45}$ The same type of association involving folate intake and metabolism, including increased frequency of the $677 \mathrm{~T}$ allele of methylenetetrahydrofolate reductase, has been found for Down's syndrome in some studies, ${ }^{6-8}$ but has not consistently been found in others. ${ }^{9-14}$ The effect of this polymorphism depends on individual folate status, mainly related to intake. ${ }^{15}$ Several other interactions involve maternal and fetal genotypes for methylenetetrahydrofolate reductase and other enzymes of the folate pathway. ${ }^{5}$

Barkai et al recently proposed that as neural tube defects and Down's syndrome are both associated with disturbances in the folate pathway, at least some cases of neural tube defects and Down's syndrome could be expected to have a common aetiology ${ }^{16}$ They verified that families at risk of neural tube defects had an excess of Down's syndrome cases and that families at risk of Down's syndrome had an excess of neural tube defects cases, establishing a link between the two conditions. They described links between neural tube defects and Down's syndrome in two different populations, an Israeli population of families at risk of neural tube defects and a Ukranian population of families at risk of Down's syndrome. ${ }^{16}$ To discover if this reported link between Down's syndrome and neural tube defects could be replicated in other conditions, we looked for it in a South American population.

\section{Methods}

To make our results comparable we followed the definitions of Barkai et al, selecting families in which a neural tube defect (anencephaly, spina bifida, or cephalocele), congenital hydrocephalus, or Down's syndrome had occurred. ${ }^{16}$ The cases were registered at birth in the Latin American collaborative study for congenital malformations (ECLAMC), ${ }^{17}$ between 1982 and 2000, from 1583838 live births and stillbirths examined in hospitals in 10 South American countries (Argentina, Bolivia, Brazil, Chile, Colombia, Ecuador, Paraguay, Peru, Venezuela, and Uruguay). We verified the occurrence of any of these diagnoses (neural tube defects, hydrocephalus, or Down's syndrome) in all probands' previous full siblings and maternal half siblings, live born or stillborn. A trained paediatrician obtained this information by taking a history from the mother after the birth of the proband. The paediatrician tried to obtain the same level of clinical details for the affected sibling as for probands, as the informer was the mother of both of them. Obviously, as for any newborn series, only previous siblings were available.

To calculate the expected frequency of Down's syndrome for all pregnancies previous to the birth of an infant with a neural tube defect or hydrocephalus from the same mother, we multiplied the number of mothers within each interval of age by the absolute risk of Down's syndrome at that maternal age, as obtained from the same birth series (data available on request). We summed the obtained expected number of cases of Down's syndrome for each year interval to give the total expected number of cases.

We calculated the expected number of cases of neural tube defects or hydrocephalus for all pregnancies previous to the birth of a baby with Down's syndrome in the same mother by using the observed birth prevalence of neural tube defects plus hydrocephalus $(0.00213)$ in the same South American population. To avoid possible bias due to significant trends in 
Table 1 Observed and expected number of cases of Down's syndrome in sibships at risk of neural tube defects or hydrocephalus and cases of neural tube defects or hydrocephalus in sibships at risk of Down's syndrome

\begin{tabular}{lccc} 
Cases & $\begin{array}{c}\text { Condition for which } \\
\text { pregnancies were at } \\
\text { risk }\end{array}$ & Observed No & Expected No $\left(\mathbf{9 5 \%} \mathbf{C l}^{*}\right)$ \\
\hline Down's syndrome & $\begin{array}{c}\text { Neural tube defects or } \\
\text { hydrocephalus }(\mathrm{n}=5404)\end{array}$ & 5 & $5.13(0$ to 11) \\
\hline $\begin{array}{l}\text { Neural tube defects or } \\
\text { hydrocephalus }\end{array}$ & $\begin{array}{c}\text { Down's syndrome } \\
(\mathrm{n}=8066)\end{array}$ & 12 & 17.18 (8 to 27) \\
\hline
\end{tabular}

${ }^{*}$ Confidence limits from Poisson distribution.

prevalence in the period studied, we also calculated the expected number of neural tube defects or hydrocephalus by calendar year of birth of siblings by using the observed birth prevalence of neural tube defects plus hydrocephalus for each calendar year.

\section{Results}

We found 5404 full and half siblings previous to 3373 probands with neural tube defects or hydrocephalus and 8066 full and half siblings previous to 3095 probands with Down's syndrome (tables 1 and 2). We observed five cases of Down's syndrome among siblings of infants with neural tube defects, compared with 5.13 cases expected according to maternal age distribution (table 1). We observed 12 cases of neural tube defects or hydrocephalus among siblings of infants with Down's syndrome, compared with 17.18 cases expected on the basis of the birth prevalence of neural tube defects plus hydrocephalus; 12 is within the $95 \%$ Poisson confidence limits (8 to 27 ) for a figure of 17 . When we used observed and expected prevalences adjusted by calendar year, 11.21 cases of neural tube defects or hydrocephalus were expected (12 observed) among siblings of infants with Down's syndrome. The two expected numbers are not significantly different, but the second one corrects possible bias introduced by the combination of older age of previous siblings with Down's syndrome and increasing time trends for prevalence of neural tube defects.

Table 2 shows the observed numbers of affected siblings separately for neural tube defects and hydrocephalus, showing the same results. This table also shows how many times more often $(\lambda)$ siblings were affected than the general population, for each diagnostic category. The risk observed for neural tube defects in maternal half siblings of infants with neural tube defects was half of that observed for full siblings, as expected with a decrease of one degree of relationship in multifactorial diseases. ${ }^{18}$ The same was true for the risk of hydrocephalus in siblings and maternal half siblings of infants with hydrocephalus. Crossed recurrences (neural tube defects in siblings of infants with hydrocephalus) showed the same risk for full siblings or maternal half siblings, and these risks did not differ from the general population risk.

\section{Discussion}

Barkai et al found an excess (11 observed $v 1.87$ expected) of Down's syndrome among pregnancies that occurred before or after the birth of a proband with a neural tube defect or hydrocephalus in a series of 493 Israeli families. ${ }^{16}$ They also found an excess of neural tube defects or hydrocephalus cases $(7$ observed $v 1.37$ expected) among pregnancies before or after the birth of a proband with Down's syndrome in a series of 516 Ukranian families. The authors were testing the hypothesis that, at least in a proportion of cases, Down's syndrome and neural tube defects could have a common aetiological pathway, probably linked to abnormal intake or metabolism of folate. We could not replicate these findings in a South American population; we found neither an excess of Down's syndrome in families at risk of neural tube defects or hydrocephalus nor an excess of neural tube defects or hydrocephalus in the families at risk of Down's syndrome.

Furthermore, if a common aetiological pathway is accepted for some cases of Down's syndrome and neural tube defects, both defects would occur in the same infant more frequently than expected. Källén et al studied 5581 cases of Down's syndrome and found no association with anencephaly, spina bifida, cephalocele, or hydrocephalus. ${ }^{19}$ Thus the association of Down's syndrome and neural tube defects described in one case by Al-Gazali et al apparently has no epidemiological support. ${ }^{8}$

The link between Down's syndrome and neural tube defects found by Barkai et al could be real or a consequence of ascertainment bias. ${ }^{16}$ They ascertained the population of neural tube defects in a genetic clinic where the parents were seeking counselling. The Down's syndrome series from Ukraine included, at least for one year, all cases detected prenatally and postnatally in a given region. Furthermore, the Israeli series was 16 years older (1971-2001) than the Ukranian series (19872001), which could increase the probability of the birth of infants with Down's syndrome in the Israeli series, perhaps as a result of recent folate supplementation policies. Two control series with other types of defect were studied in both centres to assess the possibility of surveillance bias. ${ }^{16}$ The control series contained half the number of pregnancies included in the series with cases of Down's syndrome or neural tube defects. The mean number of pregnancies described for families at risk of neural tube defects was 2.7 compared with 2.4 described in the Israeli control families; the mean number of pregnancies for families at risk of Down's syndrome was 3.2 compared with 1.8 described for Ukranian control families. The smaller sample size of the control series and the smaller size of the sibships in control families than in case families could have diminished the probability of finding an excess of Down's syndrome or neural tube defects among the control pregnancies. Moreover, size of sibship is highly correlated with maternal age, and the use of maternal age in years to calculate the expected numbers of cases of Down's syndrome could not compensate for differences of months in maternal age of cases and controls.

The other possibility is that the link between neural tube defects and Down's syndrome is real and the flaw is in our South American series. We studied a single newborn sample, in the same time period (1982-2000), ascertained in the same way for Down's syndrome, neural tube defects, and hydrocephalus. We studied only the pregnancies previous to the birth of an infant with neural tube defect, hydrocephalus, or Down's syndrome. As Barkai et al described the same excess of Down's syndrome and neural tube defects in the births occurring before and after the birth of the proband, ${ }^{16}$ this does not seem to explain our different findings. Abortion is illegal in all South American countries, so prenatal diagnosis is not routine. Some of the cases of Down's syndrome that were prenatally diagnosed in Israel would probably die without diagnosis in South America. However, this would not interfere with our findings, as we calculated the expected number of cases of Down's syndrome by using absolute risks from the same population, substantiated over 3 million stillbirths and live births. The sample we studied was also large enough to show a link even if it was not as strong as the one found by Barkai et al. ${ }^{16}$ Another possible pitfall of our congenital malformation registry material could be the under-registration 
Table 2 Prevalence of neural tube defects, hydrocephalus, and Down's syndrome in newborn population (probands) ( $\mathrm{n}=1583$ 838) and siblings of probands

\begin{tabular}{|c|c|c|c|c|c|c|c|c|c|}
\hline & \multicolumn{3}{|c|}{ Neural tube defects $(n=2421)$} & \multicolumn{3}{|c|}{ Hydrocephalus ( $(\mathrm{n}=952$ ) } & \multicolumn{3}{|c|}{ Down's syndrome (n=3095) } \\
\hline & Observed No & $\%$ Risk $\left(95 \% \mathrm{Cl}^{\star}\right)$ & $\lambda$ & Observed No & $\%$ Risk $\left(95 \% \mathrm{Cl}^{*}\right)$ & $\lambda$ & Observed No & $\%$ Risk $\left(95 \% \mathrm{Cl}^{*}\right)$ & $\lambda$ \\
\hline $\begin{array}{l}\text { Prevalence in newborn } \\
\text { population }\end{array}$ & & 0.15 & & & 0.06 & & & 0.19 & \\
\hline \multicolumn{10}{|l|}{ Neural tube defects } \\
\hline Full siblings $(\mathrm{n}=2967)$ & 49 & 1.65 (1.22 to 2.15$)$ & 10.8 & 5 & $0.17(0.05$ to 0.35$)$ & 2.8 & 3 & 0.10 (0.02 to 0.25$)$ & 0.52 \\
\hline Half siblings $\quad(n=913)$ & 7 & 0.77 (0.30 to 1.44$)$ & 5.0 & 1 & 0.11 (0.00 to 0.43$)$ & 1.8 & 1 & 0.11 (0.00 to 0.43$)$ & 0.56 \\
\hline \multicolumn{10}{|l|}{ Hydrocephalus } \\
\hline Full siblings $(n=1052)$ & 4 & 0.38 (0.10 to 0.84$)$ & 2.5 & 19 & 1.81 (1.08 to 2.71$)$ & 30.0 & 1 & 0.09 (0.00 to 0.37$)$ & 0.49 \\
\hline Half siblings† $(n=472)$ & 2 & 0.42 (0.04 to 1.21$)$ & 2.8 & 5 & 1.06 (0.33 to 2.19$)$ & 17.6 & 0 & 0.00 & - \\
\hline \multicolumn{10}{|l|}{ Down's syndrome } \\
\hline Full siblings ( $n=5919)$ & 3 & 0.05 (0.00 to 0.12$)$ & 0.3 & 6 & $0.10(0.04$ to 0.20$)$ & 1.68 & 31 & 0.52 (0.36 to 0.72$)$ & 2.68 \\
\hline Half siblingst $(\mathrm{n}=2147)$ & 1 & 0.05 (0.00 to 0.18$)$ & 0.3 & 2 & 0.09 (0.00 to 0.27$)$ & 1.55 & 3 & 0.14 (0.03 to 0.34$)$ & 0.71 \\
\hline
\end{tabular}

$\lambda=$ risk ratio for type of relative of affected person compared with prevalence in newborn population.

${ }^{*}$ Calculated as $\left(\sqrt{ } \mathrm{a} \pm \frac{1}{2} Z_{\alpha / 2}\right)^{2} / n$, where a=number of affected relatives, $n=$ total number of relatives, $\alpha=0.05$. † Maternal half siblings.

\section{What is already known on this topic}

One study found an association between Down's syndrome and neural tube defects within families

New preventive measures could be implemented if Down's syndrome is also related to abnormal intake or metabolism of folate

\section{What this study adds}

No association of Down's syndrome and neural tube defect within families was found in a larger and more uniform sample of pregnancies at risk for neural tube defects or Down's syndrome

of familial affected cases as compared with genetic counselling services, which are more subject to selection bias than our series of consecutive births. However, the prevalence rate observed for each condition for siblings and maternal half siblings, in accordance with the expected rate in models for complex diseases (neural tube defects and isolated hydrocephalus), ${ }^{18}$ do not suggest under-registration. Also, the observed confidence limits of crossed recurrences-for example, neural tube defects among pregnancies at risk for Down's syndrome-included the expected values (table 2).

\section{Conclusion}

We could not confirm that Down's syndrome and neural tube defects are more prevalent than expected in the same families in the South American population studied in ECLAMC. Because of the serious implications of the question raised about common mechanisms for neural tube defects and Down's syndrome for the prevention of Down's syndrome, this should be further analysed in different populations and in different settings.

Contributors: IMO and EEC designed the study, interpreted the results, and wrote the paper. MRA retrieved data from the ECLAMC database and did the statistical analyses. All authors were responsible for revising the manuscript and for final approval of the paper. IMO is the guarantor.

Funding: The study was partially funded by Conselho Nacional de Desenvolvimento Científico e Tecnológico (CNPq), Brazil, grant number 522059/ 96-1; Fundação de Amparo à Pesquisa do Estado do Rio de Janeiro (FAPERJ), Brazil, grant number E26-171307-2; Agencia Nacional de Promoción Científica y Tecnológica, Consejo Nacional de Investigaciones Científicas y Técnicas, Argentina, grant number PICT 495 b; and Fundación René Barón. The guarantor accepts full responsibility for the conduct of the study, had access to the data, and controlled the decision to publish.

Competing interests: None declared.
Ethical approval: CEMIC IRB (International Registrations: Department of Health and Human Services (HHS), IRB00001745, IORG 0001315) approved the ECLAMC project.

1 MRC Vitamin Study Research Group. Prevention of neural tube defect: results of the Medical Research Council vitamin study. Lancet 1991;338:131-7.

2 Czeizel AE, Dudas I. Prevention of first occurrence of neural-tube defects by periconceptional vitamin supplementation. N Engl J Med 1992;327:1832-5.

3 Mills JL, McPartlin JM, Kirke PN, Lee YJ, Conley MR, Weir DG, et al. Homocysteine metabolism in pregnancies complicated by neural-tube defects. Lancet 1995;345:14951.

4 Van der Put NMJ, Steegers-Theunissen RP, Frosst P, Trijbels FJ, Eskes TK, van den Heuvel LP, et al. Mutated methylenetetrahydrofolate reductase as a risk factor for spina bifida. Lancet 1995;346:1070-1.

5 Botto LD, Yang O. 5,10-Methylenetetrahydrofolate reductase gene variants and Botto LD, Yang Q. 5,10-Methylenetetrahydrofolate reductase gene
congenital anomalies: a HuGe review. Am J Epidemiol 2000;151:862-77.

6 James SJ, Pogribna M, Pogribny IP, Melnyk S, Hine RJ, Gibson JB, et al. Abnormal folate metabolism and mutation in the methylenetetrahydrofolate reductase gene may be maternal risk factor for Down syndrome. Am J Clin Nutr 1999;70:495-501.

7 Hobbs CA, Sherman SL, Hopkins SE, Hopkins SE, Torfs CP, Hine RJ, et al. Polymorphisms in genes involved in folate metabolism as maternal risk factors for Down syndrome. Am J Hum Genet 2000;67:623-30.

8 Al-Gazali LI, Padmanabhan R, Melnyk S, Yi P, Pogribny IP, Pogribna M, et al. Abnormal folate metabolism and genetic polymorphism of the folate pathway in a child with Down syndrome and neural tube defect. Am J Med Genet 2001;103:128-32.

9 Petersen M, Grigoriadou M, Mikkelsen M. A common mutation in the methylenetetrahydrofolate reductase gene is not a risk factor for Down syndrome. $A m$ J Hum Genet 2000;67(suppl 2):141.

10 Hassold TJ, Burrage LC, Chan ER, Judis LM, Schwartz S, James SJ, et al. Maternal folate polymorphism and the etiology of human nondisjunction. Am J Hum Genet 2001;69:434-9.

11 Chadefaux-Vekemans B, Coude M, Muller F, Oury J, Chali A, Kamoun P. Methylenetetrahydrofolate reductase polymorphism in the etiology of Down syndrome. Pediatr Res 2002;51:766-7.

12 O'Leary VB, Parle-McDermott A, Molloy AM, Kirke PN, Johnson Z, Conley M, et al. MTRR and MTHFR polymorphism: link to Down syndrome? Am J Med Genet 2002;107:151-5.

13 Stuppia L, Gatta V, Gaspari AR, Antonucci I, Morizio E, Calabrese G, et al. C677T mutation in the 5,10-MTHFR gene and risk of Down syndrome in Italy. Eur J Hum Genet 2002:10:388-90.

14 Yanamandra K, Bocchini Jr JA, Thurmon TF. Absence of association of fetal MTHFR C677T polymorphism with prenatal Down syndrome pregnancies. Eur J Hum Genet 2003;11:5.

15 Jaques PF, Bostom AG, Williams RR, Ellison RC, Eckfeldt JH, Rosenberg IH, et al. Relation between folate status, a common mutation in methylenetetrahydrofolate reductase, and plasma homocysteine concentrations. Circulation 1996;93:7-9.

16 Barkai G, Arbuzova S, Berkenstadt M, Heifetz S, Cuckle H. Frequency of Down syndrome and neural-tube defects in the same family. Lancet 2003;361:1331-5.

17 Castilla EE, Lopez-Camelo JS. The surveillance of birth defects in South America: the search for time clusters: epidemics. Adv Mutagen Res 1990;2:191-210.

18 Risch N. Linkage strategies for genetically complex traits. I: multilocus models. Am J Hum Genet 1990;46:222-8.

19 Källén B, Mastroiacovo P, Robert E. Major congenital malformations in Down syndrome. Am J Med Genet 1996;65:160-6.

(Accepted 7 November 2003)

doi 10.1136/bmj.37945.610914.EE

ECLAMC at Departamento de Genética, Universidade Federal do Rio de Janeiro, Caixa Postal 68 011, 21944-970, Rio de Janeiro, Brazil

Márcia R Amorim PhD student

Iêda M Orioli professor

ECLAMC at Departamento de Genética, Instituto Oswaldo Cruz, Caixa Postal 926, 20001-970, Rio de Janeiro, and at Cemic, Buenos Aires, Argentina

Eduardo E Castilla director

Correspondence to: Iêda M Orioli orioli@centroin.com.br 